\title{
GCU
}

Glasgow Caledonian

University

University for the Common Good

\section{Intercultural competence for students in international joint master programmes}

Yarosh, Maria; Lukic, Dane; Santibanez-Gruber, Rosa

Published in:

International Journal of Intercultural Relations

DOI:

10.1016/j.ijintrel.2018.06.003

Publication date:

2018

Document Version

Author accepted manuscript

Link to publication in ResearchOnline

Citation for published version (Harvard):

Yarosh, M, Lukic, D \& Santibanez-Gruber, R 2018, 'Intercultural competence for students in international joint master programmes', International Journal of Intercultural Relations, vol. 66, pp. 52-72.

https://doi.org/10.1016/j.ijintrel.2018.06.003

\section{General rights}

Copyright and moral rights for the publications made accessible in the public portal are retained by the authors and/or other copyright owners and it is a condition of accessing publications that users recognise and abide by the legal requirements associated with these rights.

Take down policy

If you believe that this document breaches copyright please view our takedown policy at https://edshare.gcu.ac.uk/id/eprint/5179 for details of how to contact us. 


\title{
Manuscript Details
}

\section{Manuscript number}

Title

Article type
IJIR_2017_253_R2

Intercultural Competence for Students in International Joint Master Programmes

Full Length Article

\begin{abstract}
The paper reports on the study focused on the identification of intercultural competence (IC) related learning needs of students enrolled in Erasmus Mundus Joint Master Degrees. International joint master programmes pose multiple intercultural challenges for students (and those working with them). Such programmes, therefore, present a unique opportunity for IC development, given appropriate pedagogical support. Limited research on the students' learning needs specifically related to intercultural competence in this context has been undertaken prior to the current study. 42 semi-structured interviews were conducted with students, graduates, academics and administrative staff from four Erasmus Mundus Joint Master Degrees. Data on the context and nature of intercultural challenges faced by students was analysed and synthesised using thematic analysis. The main finding reported are intercultural challenges faced (their nature and context) and the IC learning needs elements. IC elements identified were structured around the IC building blocks (knowledge, awareness, skills and attitudes - KASA elements), and emerging elements of supporting capacities (intercultural critical reflection and intercultural emotional intelligence) and meta-capacity (developing IC). The paper proposes an IC theoretical model for this particular target group. The study contributes to the theoretical understanding of IC through confirming the KASA perspective from previous research and further developing the understanding of the complex and multifaceted nature of IC by linking the supporting and meta-capacities as relevant considerations. The findings contribute to the practice of developing IC and related training and support for students, firstly in the joint degrees context but also for other educational programs involving international mobility. The study reported formed a part of the Erasmus Mundus Intercultural Competence (EMIC) project funded by the European Commission.
\end{abstract}

Keywords

Corresponding Author

Corresponding Author's Institution

Order of Authors

Suggested reviewers intercultural competence; higher education; joint degrees; master students; learning needs; Erasmus Mundus

Maria Yarosh

University of Deusto

Maria Yarosh, Dane Lukic, Rosa Santibañez

Darla Deardorff, Basil Vassilicos, Alvino E. Fantini

\section{Submission Files Included in this PDF}

\section{File Name [File Type]}

+Response to Reviewer 1.docx [Response to Reviewers (without Author Details)]

+Title page.docx [Title Page (with Author Details)]

+Manuscript_revised.docx [Manuscript (without Author Details)]

+Figure 1. Spheres of IC application for EM students.docx [Figure]

+Figure 2. Erasmus Mundus Intercultural Competence (EMIC) model.docx [Figure]

\author{
+Table 1.docx [Table] \\ +Table 2.docx [Table] \\ +Table 3.docx [Table] \\ +Table 4.docx [Table] \\ +Table 5.docx [Table] \\ +Table 6.docx [Table] \\ +Table 7.docx [Table]
}


To view all the submission files, including those not included in the PDF, click on the manuscript title on your EVISE Homepage, then click 'Download zip file'. 


\section{Response to Reviewer 1}

\begin{tabular}{|c|c|}
\hline Reviewers' Comments & Our comments / actions / rebuttals \\
\hline $\begin{array}{l}\text { [Comment 1]: With regard to the } \\
\text { abstract, and although it does now } \\
\text { provide a very good and clear } \\
\text { summary of the study and its key } \\
\text { contributions to theory and practice, I } \\
\text { would reconsider the claim that "no } \\
\text { research on the students' learning } \\
\text { needs in this context has been } \\
\text { undertaken prior to the current study" } \\
\text { (Line } 4 \text {, p.1). I understand the authors' } \\
\text { viewpoint that the program has } \\
\text { received narrowed attention at } \\
\text { research level, emerging mostly as } \\
\text { object of analysis at policy level (e.g., } \\
\text { Batory \& Lindstrom, 2011; Papatsiba, } \\
\text { 2013) or of survey research (e.g. the } \\
\text { several impact surveys on Erasmus } \\
\text { Mundus graduates). Despite these } \\
\text { limitations, there are some qualitative } \\
\text { studies that examine EM students } \\
\text { learning needs: e.g., van Swet, J., } \\
\text { Brown, K. L., \& Tedla, P. K. (2013) } \\
\text { "Learning together: an international } \\
\text { master programme in inclusive } \\
\text { education"; the work of Dr. } \\
\text { Aleksandra Gulasaryan at the } \\
\text { University of Bristol also focuses on } \\
\text { the learning needs of this specific } \\
\text { student population; the edited } \\
\text { collection of Agnieszka Gromkowska- } \\
\text { Melosik and Katarzyna Hadaś ( } 2006 \text { ) } \\
\text { on studies on non-EU EM student } \\
\text { mobility does also bring insights in } \\
\text { this regard. I would, therefore, tweak } \\
\text { the language in the abstract and the } \\
\text { manuscript in this regard to something } \\
\text { like "little research has been } \\
\text { conducted" instead of "no research" } \\
\text { which puts thing in very absolute } \\
\text { terms. }\end{array}$ & Abstract adjusted \\
\hline $\begin{array}{l}\text { [Comments } 10,11,12] \text { : The main } \\
\text { aspect that remains to be addressed in } \\
\text { the manuscript concerns Comments } \\
{[10,11,12] . \text { I appreciate the clarity of }} \\
\text { the description of the steps of the } \\
\text { coding process itself. Yet, the data } \\
\text { analysis still misses a clear definition }\end{array}$ & $\begin{array}{l}\text { Section } 3.3 \text { Data analysis and Table } 3 \text { reworked } \\
\text { accordingly. Necessary related adjustments introduced } \\
\text { into the section } 4 \text { Findings. }\end{array}$ \\
\hline
\end{tabular}


of how "thematic content analysis" is understood and operationalized in the study, as well as what is the understanding of the basic coding unit and underlying descriptors. For instance, how do the authors define a theme and identify the diferente subthemes or Level 2 codes across the data set(s)? Do the authors understand a theme in the same ways as Boyatzis (1998) as a "pattern found in the information that at minimum describes and organizes possible observations and at maximum interprets aspects of the phenomenon" (p. 4) or, in a different way? The authors cite Denzin and Lincoln (2005), but they end up not explaining how "thematic content analysis" is understood in the study and why they follow a hybrid approach that combines "content" and "thematic" analyses? More importantly, how can researchers interested in replicating the author's analytical categories, namely the themes in Table 3 know the scope of these very themes? In other words, what are the different indicators or descriptors that are, for example, associated with "Context", "Nature" (for intercultural challenges) and the 7 individual IC elements? What sort of "meanings and interpretations of the reported texts" led the two coders/researchers to "label" a given segment of the data as "Context" for example? Not making these indicators explicit makes the process arbitrary and the assigning of meaning to the transcripts unclear, as claimed by several important works on qualitative data analysis (Gibss, 2007, Ritchie \& Lewis, 2003, Boyatzis, 1998, Sandelowski, Denzin and Lincoln, 2005).

I leave to the author's consideration whether to identify these descriptors or indicators in the body of the text or directly in Table 3, but I find this aspect of crucial importance regarding 


\begin{tabular}{|c|c|}
\hline $\begin{array}{l}\text { the methodological transparency of } \\
\text { the data analysis. }\end{array}$ & \\
\hline $\begin{array}{l}\text { With regard to Comment } 5[\mathrm{~b}] \text {, please } \\
\text { note that that Appendix E that features } \\
\text { the construct of Intercultural } \\
\text { Communicative Competence (ICC) is } \\
\text { part of the multi-national study } \\
\text { depicted by the wider publication } \\
\text { "Exploring and Assessing } \\
\text { Intercultural Competence", both from } \\
\text { 2006. Fantini did revise the } \\
\text { original construct of Intercultural } \\
\text { Communicative Competence (from } \\
\text { 1995) in this study that he conducted } \\
\text { between } 2005 \text { and } 2006 \text { (hence the } \\
\text { specification of an interim revision } \\
\text { date), but the publication of the model } \\
\text { is from } 2006 \text {, as the author himself } \\
\text { also cites in other works (see for } \\
\text { instance, Fantini's chapter on the Sage } \\
\text { Handbook of Intercultural } \\
\text { Competence) or the author's latest } \\
\text { empirical testing on the model in } \\
\text { another multi-national study involving } \\
\text { five countries: } \\
\text { http://federationeil.org/wp- } \\
\text { content/uploads/2012/06/Exploring- } \\
\text { Intercultural-Communicative- } \\
\text { Competence A-Multinational- } \\
\text { Perspective1.pdf (please see the } \\
\text { section } 11 \text { "References" p. } 227 \text { ). }\end{array}$ & $\begin{array}{l}\text { References in the manuscript and in the references list } \\
\text { changed accordingly }\end{array}$ \\
\hline $\begin{array}{l}\text { I am not sure whether the authors } \\
\text { "AKAS" is based on the taxonomy of } \\
\text { another author, but if it's also based } \\
\text { on the model of ICC by Fantini, the } \\
\text { designation is KASA paradigm, } \\
\text { please see, any of the works cited } \\
\text { above or } \\
\text { http://www.eslminiconf.net/lateautum } \\
\text { n2011/expandingesol.html }\end{array}$ & $\begin{array}{l}\text { Manuscript text and order of the section adjusted to } \\
\text { follow Knowledge - Awareness - Skills - Attitudes } \\
\text { taxonomy, which is not the exact order Fantini seems } \\
\text { to suggest, but which is backed up by our broader } \\
\text { literature review (see Section } 2.2 \text { and Table ) and } \\
\text { reflects our understanding of IC and the logic behind } \\
\text { the instruments used. }\end{array}$ \\
\hline $\begin{array}{l}\text { Please note that the word } \\
\text { "Communicative" is missing in } \\
\text { paragraph } 3 \text { on p.7 (Section } 2.2) \text { - } \\
\text { Fantini's (2005) model of Intercultural } \\
\text { "Communicative' Competence. } \\
\text { There's also a typo in paragraph } 4 \text { on } \\
\text { p.8 "high skills immigrants" - "highly } \\
\text { skilled immigrants" }\end{array}$ & Corrected \\
\hline
\end{tabular}


Intercultural Competence for Students in International Joint Master Programmes Maria Yarosh, University of Deusto, Spain, mariayarosh@deusto.es - corresponding author Dane Lukic, Glasgow Caledonian University,UK, dane.lukic@gcu.ac.uk Rosa Santibáñez-Gruber, University of Deusto,Spain, rosa.santibanez@deusto.es

* The first two authors contributed equally 


\section{Intercultural Competence for Students in International Joint Master Programmes}

\section{Introduction}

International education is becoming increasingly diversified in its provision and importance. Alongside the expansion of international education and mobility, there is an increased acknowledgement of the importance of developing intercultural competence (IC) (Commission of the European Communities, 2005, p. 13; Council of Europe, 2008; Lustig \& Koester, 2013; Maiztegui \& Santibáñez, 2006; Vilá Baños, 2005; UNESCO, 2009, 2013). Higher education institutions are increasingly expected to help their students develop IC (Deardorff \& Arasaratnam-Smith, 2017; Griffith et al, 2016). Although there has been a great deal of research and development in the area of IC, it is still a challenge for educational programmes that include a high degree of international mobility and novel structures. One type of such programmes, which provides particular and underexplored IC challenges and form the context of the research presented, are the Erasmus Mundus Joint Master Degrees (EMJMDs; formerly Erasmus Mundus Master Courses).

EMJMDs are joint higher education programmes that bring together students from all over the world and offer them an opportunity to study in at least two different EU countries (EMA n/d). The European Commission scholarship scheme ensures that students enrolled in these programmes will study in multicultural environments because it aims to foster academic cooperation between EU and non-EU countries by targeting both EU and non-EU candidates. Due to the very nature of EMJMDs the intentional cultural heterogeneity of the student groups and the obligatory inbuilt international mobility - these programmes seem to create unique opportunities and challenges for IC development. Furthermore, EMJMDs, which require students to spend the whole duration of the programme abroad (for non-EU students) or a major part of the one or two-year programme abroad (for EU students), combine horizontal student mobility with vertical one (Englert, 2009). This means that even students who spend their first EMJMD semester in their home country face a new academic culture (that of a higher level academic degree). In other words, the variety and complexity of EMJMD-associated culture-related challenges is such that not only are targeted IC learning interventions needed for the personal and professional development of Erasmus Mundus (EM) students', but student support in this area is needed for their immediate needs: EM students are learning how to learn successfully in this higher level academic programme, live and study in at least two different countries, work in groups with peers from different countries, as well as share flats with people from different countries.

Although the high level of complexity faced by EM students appears evident, the exact types and nature of intercultural challenges faced by EM students and the exact configuration of IC on which such learning support could be based had not been sufficiently researched. Previous collaborative projects looked into supporting intercultural competence and developing tools for various educational contexts and mobility stages (such as PLURIMOBIL ${ }^{1}$ within school level or ICOPROMO $^{2}$ for professional mobility) but not with EM student specifically. Other studies did investigate EM context specifically but were mostly policy driven (e.g Papatsiba 2013; Batory \& Lindstrom, 2011). Some studies (e.g. Gromkowska-Melosik \& Hadaś, 2006; van Swet, J., Brown, \& Tedla, 2013) discussed learning needs and acknowledge cultural challenges of EM programmes but did not investigate specifically the nature and substance of competence(s) needed to bridge these cultural challenges. Therefore, the research aim of this paper is to investigate the learning needs of EM students in terms of diverse intercultural challenges they encounter and particular IC elements required for tackling intercultural situations. The current paper reports on the results of a research project ${ }^{3}$ whose aim of which was to identify the learning needs of EM students in relation to IC development. As EM students' IC learning needs was an underexplored domain, the study provides the first step towards defining and closing the associated research gaps.

\footnotetext{
${ }^{1}$ http://plurimobil.ecml.at/

2 http://archive.ecml.at/mtp2/Icopromo/results/

3 Part of the EMIC Project, http://www.emic_project.org
} 
In the subsequent sections we consider the theoretical framework of the study, describe the data collection procedures, present a sample and the results obtained. A discussion follows which explores the IC configuration identified as relevant for international master programmes with in-built mobility and situates it within a more general context of IC studies.

\section{Intercultural Competence in the Erasmus Mundus context}

Two major aspects are to be considered when we analyse IC development needs for a certain group of people. Firstly, it is important to clarify the intercultural challenges these individuals face: under what circumstances and what for they need to interact with representatives of different cultures. Next, it is necessary to identify particular IC elements (skills, attitudes, etc.) these individuals need to deal with cultural differences effectively and appropriately in their particular context(s) and role(s). It is necessary to explore these two aspects to establish a framework in which empirical work on intercultural competence could be developed and conducted. Sections 2.1 and 2.2 outline relevant literature on intercultural challenges students face and IC models in order to form a theoretical framework for the project on IC in EM. Section 2.3 explains why further empirical research was required to identify the IC needs of students enrolled in international master programmes with in-built mobility.

\subsection{Intercultural challenges}

When considering the intercultural challenges students can encounter, it is instrumental to describe the context in which such challenges tend to occur and the nature or reasons behind the challenges. This is paramount in the current study because our global aim is to develop a training programme to help students address these challenges more effectively and appropriately.

Research on mobile students in general (Cushner \& Karim, 2004), as well as on EU students who moved within the EU under the Erasmus programme (Atkinson, Kelly, \& Morón, 2006; Beaven, Borghetti, Van Maele \& Vassilicos, 2013, Byrla \& Domansky, 2015) distinguished two types of contexts: the academic world and the wider space of the new national culture. Both appear to be relevant for EM students as well. Indeed, a study conducted by four members of the EMIC project suggested that EM students do experience intercultural issues in both academic and non-academic contexts during their masters years $(93,37 \%$ of respondents out of $\mathrm{N}=626$ sample confirmed experiencing problems related to interculturality during their EM experience (Lukic, Yarosh, \& Martins, 2011; Martins et al., 2015)).

A third context in which EM students or graduates could require IC, is in the world of work. It might not necessarily be relevant during their masters years, but it will certainly become so after graduation. Other recent studies of mobile students' intercultural needs have also included it into their analysis (Beaven, Borghetti, Van Maele \& Vassilicos, 2013, 13). Although these contexts of intercultural challenges for EM seem intuitive, further empirical study might be required to ascertain students' perception around the relative relevance of these contexts.

As for the nature or cause of intercultural challenges; no studies had been conducted on the EMJMD population. The TEMCU project proposed a two-element categorisation: the differences between national and academic cultures; and the language barrier (Soriano \& Soriano, 2006). Although valid, this approach could not be considered sufficiently informative to base the intended intercultural training on. As a result of the more pronounced degree of cultural diversity (due to the intentional heterogeneity of student groups), the EM students' situation is more complex than that of most other mobile students. This is because (1) students normally move to a second foreign country after one academic year or even one semester; (2) within the student group there is a diversity in age and life experience (some students join EM masters directly after completing their first degree, with no previous international experience; the majority have worked for at least a short period of time and/or lived abroad before; and quite a number of students have children, occupy important positions in their 
home countries, etc.); and (3) many EMJMDs are intentionally interdisciplinary in nature, which means that students will also come from different disciplinary traditions.

From the theoretical framework point of view this led us to consider if we could build on the existing classifications of dimensions along which cultures tend to differ (Hofstede, 2001; Trompenaars \& Hampden-Turner, 1997; House et al., 2004). To be more specific, previous studies emphasise that certain core values vary from culture to culture and certain fundamental questions are often resolved differently: do certain individuals have the right to be considered as more important than others; to what extent is one expected to take care of their extended family group; is competition or consensus valued more in the society; how important punctuality is, etc. Empirical data was considered necessary to evaluate the validity of this assumption and to better determine intercultural challenges to be featured in EMJMD IC training activities.

\subsection{Intercultural Competence Elements}

What IC elements do EM students need to develop in order to deal successfully and appropriately with the multiple intercultural challenges and the cultural diversity they encounter in general? This was the second major question that guided us to develop our theoretical framework.

The literature review was guided by two principles. First off, given our research question, the models that could help us had to be compositional, rather than, for example, developmental or adaptational (Spitzberg \& Changnon, 2009, 10). Second, given the target audience, the models we prioritised were those developed for higher education students and/or (young) adults.

Although there exists quite a number of IC models that fit our two principles, there are no models that reflect the needs of EM students in particular. Indeed, no matter what type of student mobility, the diversity training discussions focus more on pre-/during- or post-departure training than on the exact components of IC students need (Cushner \& Karim, 2004). Despite the fact that higher education institutions have been sending students abroad and receiving international students for quite some time, few intercultural competence models look at student context. Most previous models cover relevant elements of IC in different ways, but could be further detailed in order to tackle IC holistically and appropriately for the EM context. It became clear at this stage that a model needed to be developed based on the previous research and after collecting empirical data. Existing models of IC developed in other contexts (migration studies, workplace setting, youth work etc.) were reviewed in order to gain a comprehensive overview of elements IC is believed to consist of. The models we reviewed were as follows: King \& Baxter Magolda's (2005) model of intercultural maturity, Williams' (2009) reflective intercultural competence, Fantini's (2006a) model of intercultural communicative competence, Byram, Nichols \& Stevens' (2001) model of intercultural communicative competence, Ang and Van Dyne's (2008) cultural intelligence model, and Deardorff's (2008) intercultural competence model. Our focus was on the IC elements distinguished.

Two relevant models that were developed explicitly for tertiary education students - the developmental model of intercultural maturity (King \& Baxter Magolda, 2005) and the reflective model of intercultural competency (Williams, 2009) - offer valuable insights into some of the aspects of IC. Yet, both of these models cater for markedly different contexts: undergraduate students who meet cultural diversity in their own country (the former) and undergraduate students who go abroad for a semester or two (the latter).

King and Baxter Magolda's model (2005) was designed for students who face cultural diversity in their own country and who should become interculturally competent citizens. Building on the work of Kegan (1994), authors further develop the three dimensions of development (cognitive, intrapersonal and interpersonal) with maturity stages. Although the model offers relevant distinctions, especially between interpersonal and intrapersonal perspectives, the stages are represented through statements and examples rather than the more detailed sub-elements of these stages. The authors primarily focus on IC development stages, with some details on the building 
blocks (Spitzberg \& Changnon, 2009, 10). Moreover, these studies involved a markedly different target audience type and context from that of EM.

Williams (2009) proposed another model based on wider studies on intercultural communication (Gudykunst, 1991; Ting-Toomey, 1999; etc.). This model focuses on intercultural learning relevant for students who spend a semester or an academic year abroad. It distinguished three IC dimensions: cognitive, affective and behavioural, which served to formulate intended learning outcomes for the study-abroad period. Due to its focus on one foreign/host culture, Williams' model has limitations for implementation in the multi-culture Erasmus Mundus context. Moreover, what is instrumental for setting feasible learning outcomes for a short period cannot satisfy the needs of EM students, who are often more mature, spend a longer time abroad in more than one foreign country and who need such a configuration of IC that will permit them to become intercultural professionals and citizens, in addition to being intercultural students. Therefore, both of these student focused models did not entirely fit the requirements of the present exploratory study.

Fantini's (2006a, 2) model proposes four types of elements: knowledge, awareness, skills, and attitudes. Awareness is often neglected (Hofstede, Pedersen \& Hofstede, 2002; Gairín Sallán et al., $2009,13)$, but, as Fantini observed, it "is central and especially critical to cross cultural development", which is "furthered through developments in knowledge, positive attitudes, and skills, and in turn also furthers [students'] development" (2006a, 2). Fantini (2006a) does not define his dimensions when describing the model, but his questionnaire (2006b) reveals what he includes in each of them. Thus, knowledge dimension includes culture-specific knowledge of the host culture, comparative knowledge of the host culture in relation to one's own culture, conceptual knowledge about what culture is, knowledge of cross-cultural adjustment stages, as well as knowing how to learn more about a new culture (and language). Attitude dimension is about ones' willingness to interact with representatives of a new culture, to learn about a new culture, to adopt new behaviours, to suspend judgement and to control one's emotions.

The skills important for interculturally competent behaviour are flexibility in one's behaviour, the ability to realise the appropriate behaviour in the given situation and adopt that behaviour. Furthermore, relevant skills also include active and self-directed learning about a new culture, comparing the new culture with ones' own, the ability to resolve conflicts and act as an intercultural mediator, as well as managing the re-entry to the home country. As for awareness, it refers to being aware of cultural differences, of ones' own reactions to them, of cultural conditioning, how representatives of another culture perceive you, the necessity to adopt new behaviours, heterogeneity of the host culture and the danger of overgeneralising of ones' own and others' current level of IC, as well as of enablers and obstacles for further IC development.

In comparison to the previously discussed student-focused models (King \& Baxter Magolda, 2005; Williams, 2009), Fantini's (2006a) proposal demonstrates that each of the dimensions comprises many different elements, each of which might be crucial for successful intercultural interactions. It is also clear that - no matter how many dimensions are distinguished - they are not fully separate entities but rather linked and overlapping elements that form a complex competence. Fantini's model was also tested in a study with incoming mobility students and highly skilled immigrants, proving the model's operationalisation in a student context although not that of joint degrees (Almeida et al., 2016).

Byram (1997; Byram, Nichols \& Stevens, 2001) distinguished similar types of components: knowledge, skills and attitudes, "complemented by" critical cultural awareness. However, Byram's understanding of the four is not the same as that of Fantini (2006a). More specifically IC is built by knowledge about cultures in general and knowledge of particular cultures; skills of interpreting and relating, and skills of discovery and interaction; attitudes of "curiosity and openness, readiness to suspend disbelief about other cultures and belief about one's own" (Byram, Nichols \& Stevens, 2001, 5); and finally the "ability to evaluate, critically and on the basis of explicit criteria, perspectives, practices and products in one's own and other cultures and countries" (Byram, Nichols \& Stevens, 2001, 7). The differences can be explained by the fact that Byram's (1997) primary objective was to 
help school children develop intercultural competence while learning a foreign language, while Fantini (2006a) worked with (young) adults-volunteers in a foreign country. Interestingly, Byram's (1997) model has the same three "layers": those related to particular cultures, those focused on cultures on a more theoretical level, and those related to the learning dimension (although much closer to acquiring culture-specific and culture-comparative knowledge than to IC development in general).

Ang and Van Dyne's (2008) concept of cultural intelligence also differentiates four types of elements necessary for effective functioning in situations with cultural diversity: knowledge, motivation, behaviour and strategy. The knowledge component here includes culture specific knowledge, on the one hand, and conceptual knowledge of cultures and cultural differences, on the other. The motivation comprises curiosity and a willingness to experience other cultures and interact with culturally-different people. The behaviour element amounts to being able to adapt own behaviour, while the strategy involves learning about cultures (culture-specific knowledge acquisition and learning from one's personal experience), as well as testing the cultural knowledge to check its accuracy. This means that awareness is not distinguished as a separate component, while developing the competence is.

Deardorff (2008) does not speak of awareness as a distinct IC building bock, but rather considers it a knowledge and comprehension component; the other components being attitudes (curiosity, tolerating ambiguity and uncertainty, openness, respect for cultural diversity and differences), skills (analysing, evaluating and relating; listening, observing and interpreting), desired internal outcomes (e.g. ethnorelative view or flexibility) and desired external outcomes (behaving and communicating effectively and appropriately). The latter two demonstrate that the researcher wanted to speak both of the nature of IC elements and the order in which they can be developed. More interestingly, the desired outcomes are more IC-specific than skills, which are very general. In other words, Deardorff's (2008) model indicates that certain components of IC are generic but their development is equally indispensable for a person to become interculturally competent.

The review and synthesis of the IC models considered as well as understanding the EM context resulted in the conclusion that an EM IC model could be expected to comprise at least four types of elements: knowledge, awareness, skills, and attitudes (KASA). Although some studies list the KASA acronym in the order of 1) knowledge, 2) attitudes 3) skills and 4) awareness (Fantini \& Tirmizi, 2006, 28 ), in our study we believe that the knowledge, awareness, skills and attitudes order signifying the KASA acronym is more logical as knowledge and awareness have great deal of connections (see Table 1). In fact, it is not uncommon for any general competence to be understood as comprising KASA (Santibáñez, Cruz \& Eizagirre, 2005, 123). As the models synthesis in Table 1 outlines, each of the six models relevant for the context addressed the KASA elements although they might not be termed in exactly the same way.

[Table 1 around here]

Subsequently, KASA was taken as a starting theoretical framework for intercultural competence in the current study with Erasmus Mundus students. Based on the reviewed literature and the EM context, the study focused not only on IC in general, but also asked respondents about specific individual competence features they considered necessary for EM students to be able to interact both successfully and appropriately with culturally different others.

\subsection{Research gap}

The literature review highlighted several research gaps relevant for exploration in IC. Firstly, there is a lack of empirical data and the literature on student mobility provides limited information on the needs of mobile students, in particular from an intercultural point of view (Bažec, 2016).

Secondly, it could be argued all the three broad spheres - academia, social sphere and the world of work - would relevant for EM students, similar to any other mobile students. However, to confirm this notion and to obtain more detailed information necessary for developing a training programme, 
empirical data on the contexts and the nature of intercultural challenges faced by EM students was needed.

Thirdly, the existing models and related training recommendations often focused on culture specific knowledge (information about aspects of a particular culture). As EM students move between a variety of cultural contexts and interact with culturally different individuals at various levels of their experience, understanding characteristics of only specific cultures and acquiring culture-specific knowledge might not be sufficient to address the complexity of situations they face. Further to this, there is a growing interest in presenting IC as transferable. Both of these aspects require attention to the processes that underpin cultural issues and interpersonal interactions rather than culture-specific knowledge only. Therefore, there was a need to examine a more generic and constructivist understanding of IC (Busch, 2009) EM students could make sense of and use in the diverse conditions they are placed in, which do not necessarily tie to a specific culture.

Lastly, no model designed for the target population or for a population similar enough could be found in the literature. The review of other well-established models also did not provide a solution that could be adopted directly. The review and synthesis did result in a hypothesis that a knowledge-awareness - skills - attitudes (KASA) framework might be instrumental for structuring the different IC elements EM students need to develop. Thus, even though the study was open and exploratory, questions focused specifically on the students' needs in terms of IC-related awareness, knowledge, attitudes and skills in the data collection instruments. Although the literature suggested that the KASA framework might be relevant it required confirmation by application of this proposed structure to the sample. These four identified gaps created the basis for the study and provided a rationale for exploring the subject empirically.

\section{Methodology}

A qualitative study was undertaken to identify EM students' learning needs in their development of IC. An IC model has subsequently been proposed on which IC training for EM students could be based. This section outlines the sampling method, the data collection procedure and instrument and data analysis employed.

\subsection{Sample}

The sample was a combination of a convenience and stratified sampling approach to ensure that different views were represented ( $1^{\text {st }}$ and $2^{\text {nd }}$ year students, graduates, academics and administrators). All respondents came from one of the four EMJMDs:

- European Masters in Lifelong Learning Policy and Management (MALLL),

- Global Innovation Management Master (GIM),

- Master in Media Engineering for Education (EUROMIME), and

- Work, Organisation and Personnel Psychology (WOP-P).

A total of 42 interviews were conducted (Table 2): twenty current EM students (16 first-year students and 4 second-year students), nine graduates, nine academics and four administrative support staff; making a total of 29 students and graduates for whom the training was to be developed, and 13 academics and administrative staff. In representation of the different programmes; 7 respondents were from EUROMIME, 11 from GIM, 11 from MALLL and 13 from WOP-P.

[Table 2 around here]

The gender sample of students and graduates was reasonably balanced: $52 \%$ males and $48 \%$ females. They came from a range of countries (Serbia - 3, Spain -3, Albania -2, India -2, Indonesia -2, Italy -2, Argentina -1, Bulgaria -1, Canada -1, Chile -1, China/Hong Kong -1, Colombia -1, Ethiopia - 1, Germany -1, Mexico -1, Moldova -1, Portugal -1, Turkey -1, Ukraine -1, and USA-1). There was also 
a diverse range in student and graduate age bracket groups: $20-24-4$ respondents $(13.8 \%)$; $25-29-16$ respondents $(55.2 \%) ; 30-34-7$ respondents $(24.1 \%)$, and 35-39. -2 respondents $(6.9 \%)$.

Most students lived abroad before the start of their EMJMD course (66\%). The majority of students reported having intercultural relationships (work or private) prior to undertaking an EMJMD (76\%), while some students reported limited $(21 \%)$ or no previous intercultural relationships $(3 \%)$. In their previous experience with intercultural training, the vast majority of students had no prior experience (74\%). A couple of students had some partially related training experience (7\%) and $19 \%$ of student had some training related to intercultural issues.

\subsection{Data collection and instrument}

Data on EM students' IC learning needs was collected through a series of semi-structured interviews conducted face to face or via Skype, between February and May 2014. The interview scripts (see Appendices A and B) were developed on the basis of the projects' theoretical framework and the findings of the previous quantitative training needs study (Martins et al., 2015) to create the following four aims:

1. Identify the respondents' intercultural profile

2. Gain insight into respondents' IC level and their learning needs

3. Find out if any IC training is already offered within the programme and students' opinion on the IC training in general

4. Gather information about the respondents' preferred learning style or IC development strategies

The interview questions aimed to determine EM students' learning needs in reference to what they wanted to develop, aspects they lacked when they started their masters, and aspects they believed an IC training should address. As the study was exploratory, it was decided not to adopt a rigid classification of IC elements, but still test if differentiating the four broad element types (Knowledge, Attitudes, Skills and Awareness (KASA)) would be instrumental for the given sample and context. Respondents were therefore asked not only about IC in general, but also about KASA perceived as important, KASA students developed naturally versus KASA they lacked and/or wanted to develop (further). Finally, the basics principles of student-centred learning influenced the interview script development process, by considering building on the current state of the students' development, offering help when students required it and in the format that suits the learner.

Two interview scripts were used: one for students and graduates (alumni) and one for academics and administrative staff who work with EM students (for interview scripts see Appendices A and B). The initial versions of the two interview scripts were reviewed by all research project partners and the wording, general order and number of questions was revised by taking into account the feedback received. The resulting version of the interview scripts were piloted in Skype-interviews by four interviewers; one conducted a pilot interview with a student, one with a graduate, one with an academic, and one with an administrative staff representative in order to test face validity of the questions. The four pilot respondents were from one of the four sample EMJMDs (see Section 3.2) from which the answers and discussions in the pilot phase allowed for the semi-structured interview script to be finalised for the study. The full study-research interviews were conducted by the same four interviewers. Each interview lasted between 40 minutes and 1 hour and 20 minutes and were recorded (audio) and transcribed verbatim.

\subsection{Data analysis}

The interviews were analysed using NVivo software and the analysis was not limited to specific interview questions since responses to all the interview questions related to the research aim addressed in this paper were considered (responses that narrated a cultural incident or referred to the students' needs or IC elements developed / to be developed). The data was analysed using the thematic analysis approach as described by Braun \& Clarke (2006). Although several methodological authors discuss 
thematic analysis as one of the activities used in qualitative research (Denzin and Lincoln, 2005; Boyatzis, 1998) thematic analysis can be considered a robust methodological approach in its own right as long as the assumptions on which it is done are clearly outlined. Firstly, epistemologically, the present study and the wider research is rooted in pragmatisms (Tashakkori \& Teddlie, 1998) since the results were not only aimed at contributing to wider academic knowledge but also for developing an educational programme for IC for the given context. Therefore, the methodological decisions on the type of thematic analysis used were informed by the pragmatist perspective. This thematic analysis was a combination of theory-driven deductive approach and data-driven inductive approach in order to (1) explore if the aspects of IC found in other studies (KASA paradigm outlined in the literature review) apply to the cohort of EM students, yet also (2) allow for new perspectives to emerge from the data. In terms of the levels explored, the thematic analysis included the semantic level which included interpretation but did not go into latent level analysis of underlying assumptions not expressed in the text (Braun \& Clarke, 2006; Boyatzis, 1998). The unit of analysis was taken to be a theme which would be a "pattern found in the information that at minimum describes and organizes possible observations and at maximum interprets aspects of the phenomenon" (Boyatzis, 1998, p. 4). The study did investigate the frequency of themes across the data set and provides these results as illustration in the Findings section. However, the distribution and frequency of themes was used only descriptively to inform the reader about the relative prevalence of the themes possible in thematic analysis and not as the tool for quantifying and interpreting the importance of themes which is common in the related but different content analysis (Vaismoradi, Turunen \& Bondas, 2013). Based on the outlined key decisions related to thematic analysis the study employed an iterative approach of the following six steps:

1. Familiarizing with the data

2. Generating initial codes

3. Searching for themes

4. Reviewing themes

5. Defining and naming themes

6. Producing the report (Braun \& Clarke, 2006)

After transcribing the data, the initial codes were generated. As the analysis was a combination of theory-driven and data-driven thematic analysis the initial codes were informed by the literature (KASA paradigm) and created based on encountered relevant information and patterns in the data (generating initial codes). Two researchers conducted the first round of coding in parallel on separate copies of the interview transcripts. The researchers applied the coding to the transcript and exchanged a sample of their coding for consistency. This step was followed by searching for themes within the data that would be related to the study research aim and be represented across the data set. In the step of searching for themes, the researchers engaged in joint collating of codes into potential themes and collecting all data relevant to each potential theme. During the step of generating initial codes we did not use particular words as indicators, but rather relied on the meaning and interpretation of the reported text. This is due to the complex nature of IC concepts and the way in which respondents speak of them. However, in the searching for themes step, descriptors were developed for the themes in order to maintain consistency. The two researchers were guided by the literature and discussed the thematic descriptors and the related data together. After identifying the potential theme structure, the researchers double-checked if the themes worked in relation to the coded extracts and the entire data set in order to produce the thematic 'map' of the analysis (Braun \& Clarke, 2006). The process of reviewing themes followed the principle of dual criteria judging internal homogeneity and external heterogeneity (Patton, 1990) to make sure that the themes represented the data and relationships in an optimal and logical manner. Any issues and disagreements with classification were shared and resolved, and the remaining data set was checked for consistency with the thematic map and the descriptors used. The final thematic map together with descriptors for each theme is outlined in the following Findings section (Table 3) since it represents both a key account of the thematic analysis described here and the first finding of the study. The step six of producing the report is outlined in the Findings section (Section 4). 


\section{Findings}

Two broad themes should be considered when concerned with EM learning needs: (1) intercultural challenges EM students encounter and (2) the IC elements respondents believe they/their peers/EM students need to develop. Table 3 below shows the thematic map which was the result of the thematic analysis employed. The table includes the descriptors used for consistency in allocating data to each theme across the data set.

[Table 3 around here]

For data related to the intercultural challenges theme, the two sub themes were aligned with theory driven perspectives: contexts and nature of intercultural challenges. For data related to the learning needs theme, the seven sub-themes were a combination of two types: theory-driven and data-driven themes (marked with the asterisk in Table 3). The theory-driven sub-themes were: knowledge, awareness, skills and attitudes (KASA) skills. The three data-driven sub-themes were labelled 'intercultural critical reflection', 'intercultural emotional intelligence' and 'developing IC'. The following sections detail the findings structured around the thematic map for Erasmus Mundus joint masters participants, outlining patterns encountered within each of the sub-themes. The patterns within each of the sub-themes that emerged were also represented by prevalence across the data-set for delineation purposes, rather than for any establishing of importance or priority of elements (Vaismoradi, Turunen \& Bondas, 2013; Braun \& Clarke, 2006). It was therefore considered more important to clarify what aspects of IC needed to be developed than to quantify how many students were in need of developing each particular.

\subsection{Intercultural challenges faced by EM students}

Both broad types of respondents (students/alumni and university staff) were asked if they could think of EMJMD-related situations where cultural differences caused a misunderstanding or a conflict. These narratives or incidents described during the interviews were coded as "intercultural challenges".

It became evident that a number of contexts where EM students encountered intercultural challenges could be distinguished. Furthermore, it was considered instrumental to explore the reported intercultural challenges in accordance to their nature; that being what caused these challenges. The IC configuration relevant for EM students therefore needs to help the students deal with these challenges in all of the contexts defined.

Six types of intercultural challenges were distinguished according to who students were interacting with and where (Table 4). Three of the challenges (1-3) were due to participants pursuing a special master programme in a number of foreign universities. The other three (4-6) were related to living abroad and changing countries during the programme of study.

[Table 4 around here]

The following (not mutually exclusive) types of nature were subsequently considered as pointing to different types of causes behind intercultural challenges:

1) Behaviours: challenges related to different behaviours considered acceptable in different cultures (behaviours and their interpretations);

2) Communication: challenges related to communication and different communication styles in particular;

3) Values: challenges related to "fundamental" cultural differences such as Hofstede's cultural dimensions;

4) Low IC Others: challenges related to perceived lower level of IC of others involved;

5) Low IC Own: challenges caused by the respondents' own low level of IC; and 
6) Personal Challenges: personal challenges related to moving to a different country, being away from social groups, etc.

This differentiation of intercultural challenges faced by EM students in relation to what caused them is not necessarily a classification of such challenges; in that a challenge reported can have more than one cause. For example, many challenges coded as "behaviour" (type 1) are also coded as "communication" (type 2) or "values" (type 3). The aim of differentiating intercultural challenges according to their nature was to gather additional information for the EMIC training and prioritise subsequent intervention phases of the study. The following two tables show the number of interviewees who mentioned each type of challenge (Table 5) and the number of times each challenge type was mentioned (Table 6) in order to show overall spread across the data set rather than determine priority. Table 5 focuses on the dominance of certain intercultural challenges across the sample, showing the number of respondents who identified that particular challenge for themselves or perceived as experienced by in other colleagues.

[Table 5 around here]

Table 6 provides a number of data extracts pertaining to each of the intercultural challenges. Such coding frequency could not provide any correlation conclusions. The combined information from both Table 5 and 6 , however, could be an indicator of the relative importance and occurrence of certain intercultural challenges in the given EM sample.

[Table 6 around here]

Overall, the findings show that a vast majority of the interviewees experiences difficult intercultural challenges in a variety of situations throughout their programme. These were experienced despite the previous experience of living and studying abroad or some previous diversity related training.

At a more general level, it can also be noted that the analysis of the interviews confirmed that EM students encounter cultural diversity both as students and as social beings. Furthermore, EM students expressed views that they expect EMJMDs to prepare them for their future professional life. All in all, they need to apply their IC in their personal/social life (during and after EMJMD), in academia (during EMJMD or further studies) and in the workplace (after EMJMD) (Figure 1). More specifically, the analysis highlights the importance of an academic and organizational setting for EM students and of being able to achieve satisfactory personal and professional intercultural interactions in both of them.

[Figure 1 around here]

Although the challenges students encountered focused primarily on the academic and social context, it can be concluded that EM students need to develop and utilise intercultural competence not only for those two spheres, but also for professional life in the future. The results indicate that the EM sample considered all three spheres of intercultural competence use as relevant, similar to previous studies in other contexts. What one could argue as unique for EM students is that they shift between these three spheres in the different countries throughout their course. This revealed a pronounced need to develop flexibility and transferable IC to assist the students in the multitude spheres of application. Moreover, this confirms that any learning intervention or training offered by higher education, needs to take into account the complex nature of intercultural competence and all the different spheres of IC application.

\subsection{IC elements}

Seven broad sub-themes /types of IC elements have been distinguished in an attempt to group the students' learning needs for IC development. Four were the theory-driven elements (KASA), while three emerged in the process of coding and analysis (intercultural critical reflection, intercultural emotional intelligence and developing IC). The structure and the content of the seven sub-themes are presented below and quotes are used in verbatim to illustrate the key points. 
Table 7 provides an overview of the number of times that different IC elements were referred to in the part of the interviews where respondents talked about their learning needs (respondents who were $1^{\text {st }}$ and $2^{\text {nd }}$-year EM students) or the learning needs of EM students in general (respondents who were graduates, academics and administrators), what students need to learn or become aware of to become more interculturally competent. Four types of references have been distinguished:

(1) when students or graduates reported that they themselves needed to develop an IC or ICrelated element [students reporting: for oneself];

(2) when students or graduates reported that other students in their cohort lacked an IC or ICrelated element [students reporting: for other students];

(3) when academics or administrative staff reported that EM students lacked a particular IC or ICrelated element [staff reporting for students]; and

(4) when the response given was interpreted unanimously by the research team and as a lack of certain IC or IC-related element [identified by researchers].

[Table 7 around here]

The following sections will elaborate on the types of elements identified as relevant leaning needs for the EM students.

\subsubsection{Knowledge}

The types of knowledge students appear to need go from very "logistic" knowledge of the country where one is to study, like the weather conditions and the clothes one needs to bring or the documents required by the university, on the one hand;

The weather, it's very cold. If I had been aware of that I would have asked my family to send my winter clothes earlier. [...] I think this is more about the document stuff and also for clothes, this kind of daily necessity stuff. [MALLL-G-3]

to deeper knowledge about different cultures (e.g. how people from other cultures think or knowledge about how specific cultures manifest themselves in organizational settings), on the other;

I would like to learn more about studying and working with people from different cultures. It's mostly about the way people from different, like from those cultures, actually think and approach problems, like maybe build their arguments and solutions. [MALLL-S1-3]

One of the clear-cut intermediate elements identified as required is knowledge of do's and dont's, tips on how to behave when dealing with representatives of different cultures and more specifically what behaviours to avoid: 'it would be nice if you had some kind of a list of no-go's for different countries' [GIM-S1-4]. Some interviewees also referred to less culture-specific knowledge: learning about the different areas in which or parameters along which cultures tend to differ.

The most important would be probably the way the different cultures behave in organisational settings. Because in different cultures, it depends on organisational cultures. The hierarchy, the power distance, from the psychological point of view; for me I think that would be more important and more useful. [WOPP-S2-1]

I wish I knew that cultural differences are not only in the way they we look at men and women or the way we approach professors, those are sort of superficial things that we know about, but in a way we reason, the way we approach issues, things that are more applicable to academic life. [MALLL-G-2] 
Therefore, the interviewees expressed clear views that the knowledge needed to be interculturally competent goes beyond culture-specific information and requires further conceptual understanding of how cultures are formed and how they impact behaviours.

\subsubsection{Awareness}

The interviews conducted suggest that students enrolled in joint master programmes with in-built mobility need help to develop the following three aspects of awareness. Firstly, students need intercultural awareness: awareness of the differences between cultures and of the cultural conditioning of others. Without such awareness, students cannot help reacting negatively or at least experiencing negative emotions when they encounter "strange" behaviours:

I felt that people were more closed up and very narrow-minded in the sense that they expected people to respond, act in certain ways that were familiar to them, which obviously did not happen. So this caused a lot of conflicts in the 1st semester. [WOPP-S2-2]

Secondly, there is a need for cultural self-awareness; awareness of oneself as a cultural being and that our own behaviour, views and reactions are conditioned by our own culture:

To be aware of my own taken-for-granted-ness, my own assumptions about life (...) I would like to have known this about myself. [MALLL-S1-4].

Finally, EM students also need to become aware of specific cases when cultural conditioning is at play. In addition to knowing that culture is supposed to influence people behaviours, they need to be capable of identifying this influence in practice.

It didn't work well at all, but I couldn't say if it was for cultural things or for motivation because I wasn't able to see the behaviour and assess it as ok this is a cultural thing. [GIM-S1-1]

I have this problem that I make jokes sometimes before thinking too much about it...and the people there didn't think it was really a bad joke, but she got really annoyed about it. So I don't think it relates to culture, more like personality maybe (...) Yeah, maybe my Chilean culture jokes are more common than in her culture, could be that. [GIM-S1-2]

It is important to note that awareness does not seem to develop in EM students automatically with experience, which highlights it as a clear learning need:

I don't know why, I mean I work with people from other countries, but still in my mind it's like the rest of the world isn't there, like Indonesia is the only culture, Indonesia is the only rule. [GIM-G-2],

Overall, awareness seemed to be a highly discussed element and it was one of the most referenced IC elements by both student and staff respondents. This further supports the need to recognise awareness as an explicit element of IC structure.

\subsubsection{Skills}

A variety of responses were received on the topic of skills EM students need to develop. Respondents believe they need to learn to communicate with representatives of different cultures, adapt to new cultural contexts and adopt new behaviours necessary for the culturally-new context they find themselves in, along with the ability to shift between the different cultural environments. Most respondents focused on communication skills needed for IC:

All of us had a similar issue ... communication, the way to communicate exactly what you think in a way that other people will understand you. [GIM-G-1] 
If I could have some preparation before here I would definitely think that the ability to listen to each other is very important. [EUROMIME-S2-1]

I wish I could be more daring, I wish I could be more brave to get my voice out. In our country, if you say something, if you debate something, then you're a bad person. So when you're in a class and your teacher said something you have to accept it because if you don't accept it then you are a bad person and they will call your parents because you want to fight them or something. So when I was in a class, when the teacher asks something I could never raise my hand and you will see other people from different countries they will raise their hands and try to answer and it was like I could never do it, even until now. [GIM-G-2]

Other respondents discussed skills needed for working in the team and distinguishing personal and professional roles that might be influenced by culture:

[I wish to learn] to differentiate friendship and when you are working together, the boundary there is something that I would like to develop. You can fight as much as you want when you are working but it should not affect you when you are actually interacting with people afterwards. That I really want to work on and want to develop a lot. [WOPP-S2-3]

Based on the responses, one could surmise students need to notice cultural differences, detect misunderstandings, check how ones' 'normal' behaviour is perceived, verbalise own cultural expectations and norms so as to discuss expectations from different people involved in team activities. As an example, talking about a particular incident where a respondent thought that culture played a role in a misunderstanding they experienced between groups, the respondent stated:

I do not know if they were aware that they were bothering the rest of us, or they thought that we did not care. [WOPP-G-3]

On occasion, students (with higher IC) could take a role of an intercultural mediator and/or help others with lower level of IC develop their IC further. However, although some students might identify intercultural issues they do not always take action.

Within the international group you had different religions, Muslim or different types of socialising or not going out drinking and those sorts of things, whereas the European there was maybe more in common with the local culture and that extra-curricular socialising tended to divide them a little bit and when the rep, one year when the student rep was a European guy, he reported this kind of difference to me, but didn't seem to really be doing anything about it. [GIM-A-2]

Yeah, I don't know if it's a skill, but if you're in a meeting with people and everyone is to contribute something and then you have a very loud person who talks all the time, then you have 3 others who basically might want to say something, but they're basically not really sure how to do it. I think that's a really good skill to have. [GIM-G-1].

Further to this, it is important to remember that students need help with broadening their behaviour repertoire rather than substituting old behaviours with new ones:

Here ... others ... wait to speak to you and to interact with you after you finish; no, in my home speak three or four people at the same time, and you do not understand anything. [and when I went back home for holidays I noticed that I lost this ability] to understand three people at the same time speaking. [WOPP-S1-3]

\subsubsection{Attitudes}


As for the attitudes, quite a number of them were reported as necessary: acceptance of differences or positive attitude to difference and diversity; the attitude of openness, open-mindedness or approaching things with an open mind; non-judgmental attitudes; tolerance; respect for culturally-different others; valuing diversity; a positive attitudes towards and willingness to encounter new cultures and people who are culturally-different:

Train yourself to notice differences but not to be afraid of that. Actually to see this as enrichment. At least that's what it is for me. [WOPP-S1-1]

Before coming abroad you should be aware that you should listen and be very tolerant as well, like tolerance is tough, it's difficult, but I think it's key. [EUROMIME-S2-1]

You have to be open to new experiences. [WOPP-G-1]

The cooperative mind-set; 'attitude $\ldots$ of thinking cooperatively, ... acting cooperatively and discussing things cooperatively' [WOPP-S1-4], was also mentioned; alongside a flexibility and willingness to adjust ones' own behaviour to take into account others' culturally-conditioned expectations for the desirable interaction to take place:

I think the key quality in all these international programmes is flexibility and people have to understand that before they go into it and that's something you have to be prepared for, but it's also something that you have to learn because it's not easy. [MALLL-Adm-1]

Overall, the findings show that the respondents viewed attitudes as a key element of being intercultural competent, although most discussed this aspect in general or for others rather than for oneself.

To sum up, considerable effort and support is needed to help EM students develop the wide range of complex and interrelated skills in order for them to perform well in different contexts and use the diversity as an advantage. As such, one could argue that skills represent an element of IC that might be easier to observe, whilst also confirming that behaviours reflect all IC aspects. Overall, the findings indicate clear evidence in support of the theory-driven KASA, while the analysis of the interviews also revealed the importance of three emerging elements that seem to be interconnected and add to the multifaceted nature of the learning needs of EM students. Those emerging elements were intercultural critical reflection, intercultural emotional intelligence and developing IC. Interestingly, these three elements had qualities of competences themselves and therefore also contained knowledge, awareness, skills and attitudes dimensions.

\subsubsection{Intercultural critical reflection}

Respondents emphasised different aspects of critical reflection relevant in intercultural contexts, including the capacity to overcome judgmental thinking, deal with stereotypes, generalisations or assumptions, and generally to manoeuvre between the necessity and the danger of generalising. Several respondents shared the view on importance of critical reflection on one's own behaviour, as well as that perceived in others. The interview analysis identified a number of specific learning needs related to intercultural critical reflection. Firstly, the students' capacity to deal with stereotypes personal opinions and peer views about their culture, as exemplified by WOPP-S1-1 as 'the skill of trying to behave myself without judging. Secondly, cognitive flexibility and/or ability to analyse intercultural encounters through a culturally-aware perspective and frame-shifting to see things from a different cultural perspective were considered very important. One of the academic respondents stated:

I think the problem tends to be that they're not prepared to accept that there are other ways of looking at problems or situations other than their own. [GIM-A-1]

Student respondents also supported the relevance of intercultural critical reflection: 
I think that's part of the critical thinking, that you may be wrong or somebody else may be wrong, but I think we are willing to be in a position where we say 'I may be wrong'... I have to see from your perspective and maybe it's not about being wrong or right, really it's about having different perspectives on the same situation and in that sense learn from it.... So really the ability to reflect upon a situation, and the ability to not having to always prove yourself right, I would say, is important. [MALLL-A-4]

Thirdly, respondents indicated that critical thinking should be employed when dealing with culture specific knowledge:

I would definitely like to know more, because I do not want to fall into the idea of stereotyping. Because I also like to talk about this and I do not want people to think that I think that, yes, Germans are like this, and so I am stereotyping. That is not true. I know that German can be like this but also can be the opposite. [WOPP-S1-1]

The emphasis on intercultural critical reflection indicates a special role this category plays in the IC elements configuration.

\subsubsection{Intercultural emotional intelligence}

A number of respondents highlighted the affective aspect of intercultural competence and the need to develop emotional adaptability. In this context, intercultural emotional intelligence included empathy, managing ones' emotions, dealing with uncertainty and the emotional side of perspective-taking. Whilst a number of respondents recognized this need for emotional aspect of IC, one respondent specifically addressed emotional intelligence as a learning need for IC development:

Talking more about emotional intelligence and being able to stand back and analyse the emotional situation and what's going on in terms of psychology. [GIM-S1-1]

The interviews revealed a connection between intercultural emotional intelligence and intercultural awareness of the self and others. Besides, the interview analysis indicated the importance of managing ones' own emotions and those of others through intercultural emotional intelligence. Empathy, as both a skill and an attitude, was further highlighted by respondents.

I wish I could learn to ... to have more empathy, maybe, so trying to understand what's in their mind. Well, not really in their mind... how they feel, so that I can easily get along with them.

[WOPP-S1-2]

On the basis of the interview analysis, one could argue the intercultural critical reflection category addresses elements of cognitive nature, whilst the intercultural emotional intelligence addressed elements related to the sphere of emotions. The emerging categories are not only viewed as important for the IC development of EM students, but also appear complementary and often integrated in real life scenarios.

\subsubsection{Developing IC}

It became evident from the interviews that another important learning need was that of learning how to develop IC, a meta-ability of obtaining knowledge on the topic and being able to development other IC related elements. The different fragments where respondents referred to this need or where it was observed can also be reported on following the KASA organization principle.

Meta-knowledge is about knowing what elements build IC and how IC can be developed, and therefore the knowledge of typical/possible strategies for IC development.

I don't know I'm not sure what we can really do to train yourself for things like that. [GIM-G-1] 
The data collected revealed that a smaller number of respondents did not appear to think IC could be developed, and as a result they did not reflect on how it could be developed or on what they could do to develop it. Thus, a couple of first-year students believed there was nothing for them to learn or to become better at when dealing with people from other cultures (e.g. WOPP-S1-3), whilst others believed only members from an ethnic minority should develop IC (e.g. GIM-G-2).

It was further observed that students needed to acquire the vocabulary and conceptual knowledge needed to verbally account for their progress, developmental level and IC learning needs. As evident below, some alumni were at a loss to explain what they have learned in terms of IC during their EMJMD years:

Skills, I dunno, I dunno, what I can say. [WOPP-G-2]

I learned a lot but to put it in one phrase it's kind of, or two phrases, it's difficult. [WOPP-G-3]

As for meta-awareness elements identified, a key aspect is the awareness of own identity and that it is inevitable for one's identity to be modified as an outcome of intercultural interactions. The study showed students' need to become aware of how the identity is constructed and how it may be affected in intercultural situations. Developing IC therefore requires individuals to reflect on their own identity and, without such awareness students can find themselves overwhelmed by challenging existential questions:

I cannot deal with it all like because I still have some missing points and I don't know how to behave according with [Danish - host - culture expectations], but on the other hand, I think, should I always behave according to Danes and how they do for example, so it's a bit problematic. And actually in my mind what should I do, how should I behave, should I just behave naturally how I am or like simulation? [MALLL-S1-1]

Another key aspect is an awareness of personal learning needs; strengths and weaknesses that would enable further learning strategies and development.

It might be kind of a problem explaining to you what I have learned and what I have not learned. Because it was all at once and I don't separate it. [WOPP-G-3]

This second type of meta-awareness is closely linked to meta-knowledge, described above.

This brings us to the meta-skills as part of the developing IC element. Three broad sub-categories were distinguished here. Firstly, the skills necessary to effectively obtain cultural knowledge an ability to act on one's lack of knowledge about cultures, a willingness to know more and to master the techniques necessary to acquire cultural knowledge, e.g. talking to and/or meeting foreign culture representatives and getting cultural information from them, a capacity to learn about cultures without stereotyping or developing a habit of comparing aspects of different cultures, etc.

I would like to learn more from them [members of a different culture], but I don't know how. [MALLL-S1-2]

The second meta-skill students' need is the ability to monitor their IC development and the ability to verbalise their "achievements"; including the ability to identify their strengths and weaknesses; and being able to ask for help:

It's very difficult $[\ldots]$ to realise that you are learning. You can learn, because I have learned, I know that, but I do not know what. I am converting myself in someone else, but I don't know some sense-making, some kind of sense-making, like this is happening to you. [WOPP-G-3] 
The third interrelated sub-category, is the ability to manage ones' intercultural identity development, not necessarily adapting $100 \%$ to every new culture they meet, not being excessively influenced by others' opinion, being ready to be "less excellent" in the new cultural environment.

Some [students] have great difficulties in obtaining advice because in this obtaining advice you have to be open, you have to admit that you do not know everything because otherwise it's very, very difficult to learn something. [MALLL-A-1]

Respondents cited or were observed as requiring at least four groups of meta-attitudes. First, students need to appreciate the full potential of IC, value the innovation potential of diversity. This means that they should cease to believe IC serves only to avoid intercultural conflicts or 'major problems' [GIMS1-2]. On the contrary, if they considered IC as a means of personal development and realize that it is not only for 'minorities', this would counter views such as those expressed by GIM-G-2.

Secondly, there is a need for students to embrace as much of the cultural diversity they encounter as possible, rather than focusing on a singular local culture. Otherwise, students might even develop a negative attitude to the cultural diversity within their cohort, which could then be perceived as 'distracting' them from learning more about the local culture(s):

I wish to learn more about Danes. Like the culture because I am in Denmark and after a few months, I won't be in Denmark so this is the place I should learn about Danes but I think that I am learning more about the other cultures other than Denmark because of this international group. [MALLL-S1-1]

A third, closely related, meta-attitude is that of an orientation towards a generic IC, which is to be developed on a lifelong basis. This realisation often does not come naturally to students, as one of the academics interviewed pointed out:

I think that it is very difficult to anticipate and also take into account what you should know because now you're landing in Denmark, it would have been different if you had been in the US or in the UK or in Spain or in Australia or Germany. So I mean I think that you have to take into account that this is just part of the learning process. [MALLL-A-1]

Finally, a proactive attitude was identified as the fourth IC development-related attitude. Students should obtain a proactive manner towards their IC development and take responsibility for it. For some students, like WOPP-G-2, who has 'never thought about' the ability to deal with cultural diversity as a competence and, thus, something that can be developed, such realisation is a prerequisite. Yet, even students who have reflected on the issue do not necessarily choose to become self-directed learners in this sphere. This amounts to them not fully using the unique opportunities offered by an international master programme with in-built mobility.

To conclude; how to develop IC is an important emerging learning need identified in the current study. This complex need can, in turn, be split into meta-KASA to better support students. It should also be reiterated that some students may require help with becoming aware of this meta-need first, before they can purposefully acquire the associated KASA.

\section{Discussion}

The exploratory study of EMJMDs provided useful information related to identified research gaps. Firstly, the findings of the thematic analysis reported reveal the IC-related needs for this particular category of students and, thus, contribute to bridging the first research gap identified. Perhaps most importantly, the interviews conducted confirm that even in such promising and rich learning environments as an international masters programme with in-built mobility IC cannot be fully developed without a purposeful learning intervention. Students may well believe that the mere fact of 
studying abroad in a culturally mixed group means that they have already acquired IC. Yet this is a myth (Deardorff, 2015). The interviews leave little doubt about the fact that students can develop IC naturally or unintentionally to a limited extent only. Consequently, considerable support and training are needed in order to develop generic IC - the IC not limited to a narrow application context - and especially the meta-component of IC, which in turn permits students to further develop their IC as a result of purposeful and self-regulated efforts. In accordance with other research, the data collected in this study shows a need for educational support for students to develop or further improve IC elements related to the capacity for self-regulated IC development: identifying 'own developmental stage, awareness of and capacity to speak of one's own progress, as well as seeing what to do next to improve a particular aspect of IC (Bennett, 1993; Williams, 2009).

The data related to the three application spheres, context and nature of intercultural challenges faced by the students provide responses to the second research gap. The literature review and analysis have found the three spheres of personal-social, academic and workplace key for EM students. In this respect, their needs are similar to those of other mobile students (Beaven, Borghetti, Van Maele, \& Vassilicos, 2013). The data on the context and nature of intercultural challenges have permitted to draw a clearer picture in terms of specific needs of this category of students (Atkinson, Kelly, \& Morón, 2006; Beaven, Borghetti, Van Maele, \& Vassilicos, 2013). What we have found is coherent with what could be expected, given the different dimensions of cultural diversity that come into play in an Erasmus Mundus master (section 2.1).

Two distinctive features of intercultural challenges are perhaps worth highlighting as unique for EM students: the perception of EM students as different from other students (even if international) and cultural challenges related to the complex logistics and administrative nature of the programme. Curiously, the latter can be seen as an "objective" reason for the former. Erasmus Mundus masters are indeed exceptional in terms of cultural heterogeneity, which is partly made visible through the programme logistics. However, it is important to point out that this perception of exclusivity can easily affect the students' beliefs about their IC; that it is somehow automatically higher than that of other students, and, consequently, their learning needs; both in terms of IC to be developed and misconceptions to be addressed.

The categories of identified challenges permit those not familiar with EM master programmes to gain an understanding of the complexity of the EM students' IC needs. Although crucial for achieving the face validity of any pedagogical intervention or further research, these categories should be treated as a "blueprint". The external IC outcomes EM students need to achieve (Deardorff, 2008) are multiple, diverse and unique for each student; dependent upon the students' background and aspirations. For this purpose, as the analysis of the context and the nature of intercultural challenges reported in the interviews suggests, students need to develop IC that is transferable through many contexts.

This brings us to the third research gap: the need for a generic rather than culture-specific IC was concluded in qualitative data. The findings clearly indicated that to focus on a particular cultural knowledge approach to IC development would not be sufficient for EM students. Responses obtained suggested the IC approach must be generic because of the individual and unique combination of intercultural situations and needs EM students will have to deal with during and after the master based on geographic, disciplinary or organisational cultures. The challenges faced in each of the cases will also depend on the students' unique cultural background: country of origin, upbringing, experience of living abroad, work experience, etc. Therefore, even if EM students (and alumni) often need culturespecific knowledge and might well be required to develop culture-specific skills, it seems clear that learning how to acquire such knowledge and identify and develop such skills is what students really need. This is why a generic (or transversal, transferable (González \& Wagenaar, 2008, 17)) capabilities as cognitive and emotional management appear as indispensable for IC in the context of EM. Moreover, our findings indicate an awareness of some respondents that focus on culture-specific knowledge (do's and don'ts for a certain culture) are not only insufficient for optimal IC development but could also be detrimental as they might lead to overgeneralisation for other, different, cultural contexts. A deeper and more generic understanding of the nature of culture and how it impacts one's 
own and others' behaviour is needed in other to prepare graduates for the diverse cultural situations they will be faced with.

KASA as an organisational principle has proven useful to propose an IC model from the data collected for the fourth research gap addressed by the present research project. Thus, the findings clearly confirmed the relevance of the proposed KASA theoretical framework for the sample. All respondent types agreed on the relevance of knowledge, awareness, skills and attitudes as essential for IC in Erasmus Mundus, although with some differing views as to what particular items would be included in each of these categories. This ensures data triangulation of the KASA framework and therefore that distinguishing the four types of IC elements (KASA) can be instrumental. The findings further indicate that there are other areas relevant for the overall IC of EM students. This was indicated by the emergence of intercultural critical reflection and intercultural emotional intelligence as supporting capacities that have an impact on the core KASA structure. These IC elements need to be completed with the meta-component, which reflects the need to learn how to (further) develop IC (Ang \& Van Dyne, 2008).

These findings permitted us to further develop the KASA theoretical framework into an Erasmus Mundus Intercultural Competence model (EMIC model - Figure 2). The proposed model therefore consists of IC building blocks, two supporting capacities, and a meta capacity. The four intercultural building blocks (Knowledge, Awareness, Skills, and Attitudes) and the two supporting capacities (Intercultural critical reflection and Intercultural emotional intelligence) constitute core IC. The supporting capacities underpin how elements from the IC building blocks are operationalized and developed in practice. It is important to note that although supporting capacities are singled out as underpinning support mechanism, they are closely related to the IC building blocks. Other authors did point out relevance of critical reflection and affective aspects of IC but the model proposed here includes them as complex capacities that are not only simple elements of IC but actually have an impact on all other KASA elements and their utilisation. For example, the knowledge aspect of being aware of some cultural norms of a particular culture needs to be coupled with critical reflection lest it become a stereotype potentially leading into prejudice. Another example could be a skills element of modifying your behaviour with others which without emotional intelligence and knowing how our behaviour impacts the emotions of others might lead to further blunders or redraws. Therefore pointing out intercultural critical reflection and intercultural emotional intelligence as capacities affecting the competent use and display of all other KASA elements is an important addition to our theoretical understanding of IC.

The meta capacity (Developing IC) should be developed by EM students who wish to become autonomous lifelong learners in their IC development. Therefore, students need to understand what IC is, how they can develop it further, how they can monitor their own IC development and how they can verbalise their achievements when necessary, e.g. during an interview with a potential employer. Such knowledge and awareness should be accompanied with a capacity, willingness and habit of applying them in practice. This is why the meta capacity (Developing IC), which represents the learning to learn side of IC, is considered as essential to the proposed model.

\section{[Figure 2 around here]}

The importance of the meta-component is supported by views from other scholars when discussing cultural intelligence strategies, becoming intercultural learners, and later intercultural professionals and intercultural citizens capable of developing their IC further (Ang \& Van Dyne, 2008; Byram, 1997). Ingraining Developing IC as part of the IC model rather than a surrounding discussion allows for a holistic representation of IC as a truly complex competence that consists of a number of interrelated elements that range from core elements, supporting elements and meta-developmental aspects. The EMIC model proposed here based on previous models, previous research and the reported empirical study highlights the complex demands for developing such a multi-faceted competence for both individuals and institutions involved in educational mobility. 


\section{Conclusion}

The findings reported and discussed above are a novel and significant step in the identification of ICrelated learning needs for EM students; which, in turn, contributes both to the research on IC and to IC development practice. The current study contributes an insight into the contexts and nature of intercultural challenges faced by EM students and proposes an IC model for this particular target group. The study contributes to the theoretical understanding of IC through confirming the KASA perspective from previous research and further developing the understanding of the complex and multifaceted nature of IC by linking the supporting (intercultural critical reflection and intercultural emotional intelligence) and meta-capacities (developing IC - learning how to develop it) as relevant considerations.

The IC training and support activities can help EM students (further) develop their IC, and, as the data collected suggests, should probably prioritise an awareness and "developing IC" components for the purpose of meeting students' needs (Table 6 above). However, all the complex IC elements discussed in the paper (KASA, supporting and meta capacities) require attention to counter the challenges any learning intervention programme will face because it needs to focus on catering for the very different needs of each student. A combination of face-to-face and online activities that students can select according to their developmental priorities, and which will permit each student to follow their own itinerary might be an optimal response to develop IC as a multifaceted cluster competence.

The study shows that it is important for students to conceptualise IC as a competence and thus something they can develop intentionally; to value IC development efforts and to start reflecting on their own IC level and developmental priorities.

The research context was represented by four EMJMDs, one particular type of international joint master degrees with in-built mobility. However, it is the nature and not the name of the programme which determines the learning needs, which make the results obtained applicable and relevant for a much wider circle of educational programmes. Certainly caution is warranted when these programmes are delivered outside the EU. Thus, further research is needed to see if students in areas outside the EU might face different challenges and have different priorities. It is reasonable to expect, however, that the difference will be more of a relative importance of the different IC challenges and elements identified, rather than of a type of challenge and the elements themselves.

\subsection{Limitations and future research}

The study would have benefited from a wider range of data as well as probing into motivations of the students to engage in international educational experiences that might have revealed some of the 'attitude' perspectives of their IC. Moreover, although our study did investigate foreign languages respondents were familiar with, we did not explore in detail the degree of knowing the host countries' languages and its impact on IC development and intercultural challenges faced, which could be done in future studies. However, although previous research stresses the impact of knowing languages of host countries, it is important to remember that IC here is not understood as a dyadic home-host culture competence but rather a generic and transferable competence of dealing with multitudes of cultures at a time (which is particularly important in the context of joint degrees with in-built mobility and culturally heterogeneous student groups).

The exploration of IC could benefit from employing a longitudinal approach and collecting data from the same respondents at different points of their educational mobility journey (which was not possible within this research project due to the nature of the study and the related funding). Having in mind the nature of the topic, there was a degree of likelihood of social desirability bias from the respondents that might have made them over-report certain aspects of their IC and its relevance. However, the study ensured actions to mitigate this bias through establishing an open environment during the interviews, asking open ended questions, probing claims with follow-up questions and asking for examples and the fact that the study was not part of the students' obligatory formal education. 
Further empirical work testing the proposed IC model in other educational contexts would be beneficial for the development of the field and determining the degree of generalisability of the results and outputs. Finally, the study highlighted the issue of academics' and administrators' IC and their capacity to act as facilitators of students' IC development. The interviews conducted with academics and administrators were focused on their perception of students IC learning needs and it became evident that those working with students were not always aware of the intercultural issues students face. An agenda for further research should thus review and question academics' and administrators' IC; all of which is crucial if we want programmes and institutions themselves to become interculturally competent.

\section{Acknowledgements}

This paper was based on the Erasmus Mundus Intercultural Competence study supported by the Erasmus Mundus Action 3 Grant of the European Commission. We would also like to extend our thanks to the collaborating Erasmus Mundus Consortia staff and students: Work, Organisation and Personnel Psychology (WOP-P), European Masters in Lifelong Learning Policy and Management (MALLL), Master in Media Engineering for Education (EUROMIME), and Global Innovation Management Master (GIM).

\section{References}

... [separate document]

\section{Appendix A. Learning Needs Analysis Interview Script: Students and Graduates}

1. Before coming to your EM programme, had you lived in a foreign country?

Where and how long?

What did you do?

Who did you interact with?

2. Before coming to your EM programme, had you had any significant experience/relationships with people from other cultures (in your own country)?

Can you describe it?

3. During the EM programme did you live by yourself or with people from other cultures?

How are/have been your relationships with them?

Are/Have your been only sharing the same space or were you interacting in any other ways /doing some things together?

\section{What languages do you speak? How and where did you learn them?}

5. Can you think of a situation during your EM study when you think cultural differences caused some difficulties? [an incident] Could you please describe the incident/situation?

Prompts: How about some issues with:

a) the people you study with or have to work with in study groups

b) the people you pass your free time with

c) your EMJMD professors

d) other university members

e) your flatmates

f) local people

g) any public administration representatives 
6A/B How did you go about resolving the issue?// How did those involved go about resolving the issue?

7A/B Were you satisfied with how the issue was dealt with by you/other people involved? // Do you think they dealt with the issue in a satisfactory manner?

YES $\rightarrow$ What do you think helped you to resolve it successfully? // What do you think helped them to do so?

NO $\rightarrow$ What could have helped you to resolve it successfully? What could you learn to do it better next time? // How would have you dealt with the issue? Why do you think they were unable to resolve the problem in a satisfactory manner?

8. Do you think it might be useful to develop your ability to deal with cultural diversity and differences for your further studies, your work or private life?

YES $\rightarrow$ What do you think could help you to develop your IC? Were you aware of this before you came to EMJMD?

$\mathrm{NO} \rightarrow$ Go to the next question

10. Have you been able to learn something through living and studying with people from different cultures during your EMJMD experience so far that has proved beneficial for your classroom experience/private life/working life?

YES $\rightarrow$ What is it? How did you come to learn it?

$\mathrm{NO} \rightarrow$ Go to the next question

11. Is there any knowledge you wish you had before EM which could have helped you deal better with intercultural situations during your EMJMD time? What is it?

12. Is there anything you wish you had been aware of before EM which could have helped you deal better with intercultural situations you encountered during your EMJMD time? What is it?

13. Is there something you were not able to do to deal with intercultural situations and you wish you had known how to do or do better at the beginning of EM? What is it?

14. Were there any beliefs and attitudes that you wish you had at the beginning of your EM experience to be able to deal better with intercultural situations? What are they?

15A. Is there anything in terms of living and studying with people from different cultures you wish you could learn/learn to do? What is it?

15B. [FOR THOSE WHO SEEM MORE EXEPRIENCED]: Are there any things in terms of living and studying with people from different cultures you think you could still learn?

16. Did you have any training related to intercultural issues and/or diversity prior to the Erasmus Mundus Master Course?

YES $\rightarrow$ What was it? Was it useful for you? Could you explain how? Which elements of the training were useful and which not?

$\mathrm{NO} \rightarrow$ Go to the next question

17. Have your Erasmus Mundus Universities provided you with specific support in adaptation to the new intercultural context(s)?

YES $\rightarrow$ What was it? What kind of impact did this support have on your Erasmus Mundus Experience? In what way would your EM Experience have been different if you had not had this support?

$$
\text { NO } \rightarrow \text { Go to the next question }
$$


18. Do you think it is worth having some support offered by the Erasmus Mundus universities to deal with intercultural issues? Why (not)?

What exactly can be useful? What would make you participate in that support/attend that training?

What could be done to make it useful and attractive to the students?)

19. Which of the following do you think are useful in helping you better understand and deal with situations when you have to interact with people from other cultures? Which is the most useful and why?

[select those which are relevant for the respondent you are talking to]

$\square$ having lived in a different country

$\square$ having experience of working and/or studying relationships with people from other cultures

$\square$ having experience of private relationships with people from other cultures

$\square$ speaking more than one language

$\square$ having attended intercultural training to develop skills, knowledge and attitudes

Appendix B. Learning Needs Analysis Interview Script: Academics and Administrators

1. Before you started working with [EM] students, had you lived in a foreign country?

Where and how long?

What did you do?

Who did you interact with?

2. Before you started working with [EM] students, had you had any significant experience/relationships with people/had you had friends from other cultures (in your own country)? Can you describe it?

3. Do you currently socialize with/spend time with peoples from other cultures (not EM students)?

4. Before you started working with [EM] students, had you worked with other international students?

YES -> Did you notice any change when you started working with EM students?

5. What languages do you speak? How and where did you learn them?

6. Can you think of a situation during your EM study when you think cultural differences caused some difficulties? [an incident] Could you please describe the incident/situation?

Prompts: How about some issues with:

a) the people you study with or have to work with in study groups

b) the people you pass your free time with

c) your EMJMD professors

d) other university members

e) your flatmates

f) local people

g) any public administration representatives

h) how things are done in the country you are now studying in

7A/B. How did you go about resolving the issue? Were you satisfied with how the issue was dealt with by you/other people involved? // How did those involved go about resolving the issue? Do you think they dealt with the issue in a satisfactory manner?

YES $\rightarrow$ What do you think helped you to resolve it successfully? // What do you think helped them to do so? 
NO $\rightarrow$ What could have helped you to resolve it successfully? What could you learn to do it better next time? // How would have you dealt with the issue? Why do you think they were unable to resolve the problem in a satisfactory manner?

8. Is there any knowledge you think your students lack that could have helped them deal better with intercultural situations during their EMJMD time? What is it?

9. Is there anything students tend not to be aware of but which could have helped them deal better with intercultural situations during your EMJMD time? What is it?

10. Is there anything students are not able to do to deal with intercultural situations which could be improved on? What is it?

11. Are there any beliefs and attitudes that students need to develop to be able to deal better with intercultural situations during their EMJMD time? What are they?

12. What could be done to help students learn these develop these knowledge, skills and attitudes?

13. Do [EMJMD] Universities provide the students with specific support in adaptation to the new intercultural context(s)?

YES $\rightarrow$ What is it? Are you involved? What kind of impact do you think it has on students' Erasmus Mundus Experience?

$\mathrm{NO} \rightarrow$ Go to the next question

14. Do you think it is worth having some support offered by the Erasmus Mundus universities to deal with intercultural issues? Why (not)?

What exactly can be useful? What could be done to make it useful and attractive to the students?

How can your efforts be complemented if you had all the staff, money and time needed?

15. Have you been able to learn something through working at EMJMD/with EM students in the past which you apply in your work with current students? What is it? How did you come to learn it?

16. Did you have any training related to intercultural issues and/or diversity prior to starting working at the Erasmus Mundus Master Course?

YES $\rightarrow$ Was it offered by your University? What was it? Was it useful for you? Could you explain how?

$\mathrm{NO} \rightarrow$ Go to the next question

17. To what extent you think it is useful for those who work with EM students to put effort into developing their ability to deal with cultural diversity and differences?

18. What do you think could help you develop your ability to deal with intercultural issues?

19. Which of the following do you think are useful in helping you better understand and deal with situations when you have to interact with people from other cultures? Which is the most useful and why?

[when interviewing, select those that are relevant to your current respondent]

$\square$ having lived in a different country

$\square$ having experience of working and/or studying relationships with people from other cultures

$\square$ having experience of private relationships with people from other cultures

$\square$ speaking more than one language

$\square$ having attended intercultural training to develop skills, knowledge and attitudes 


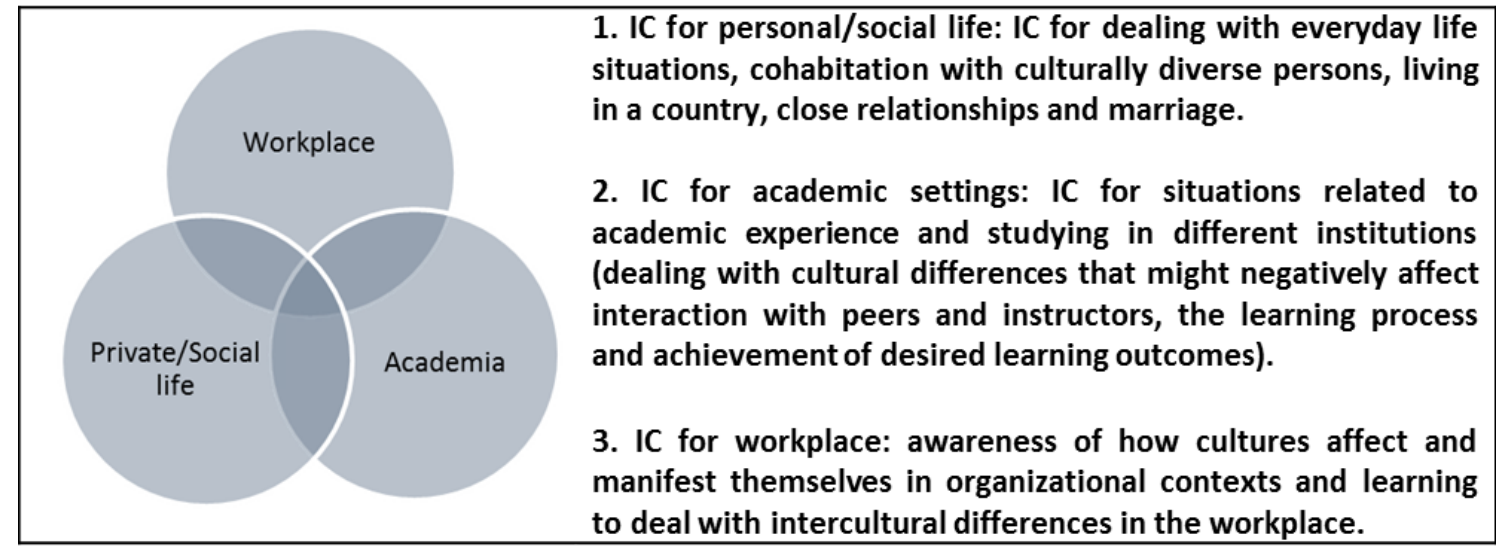

Figure 1. Spheres of IC application for EM students 


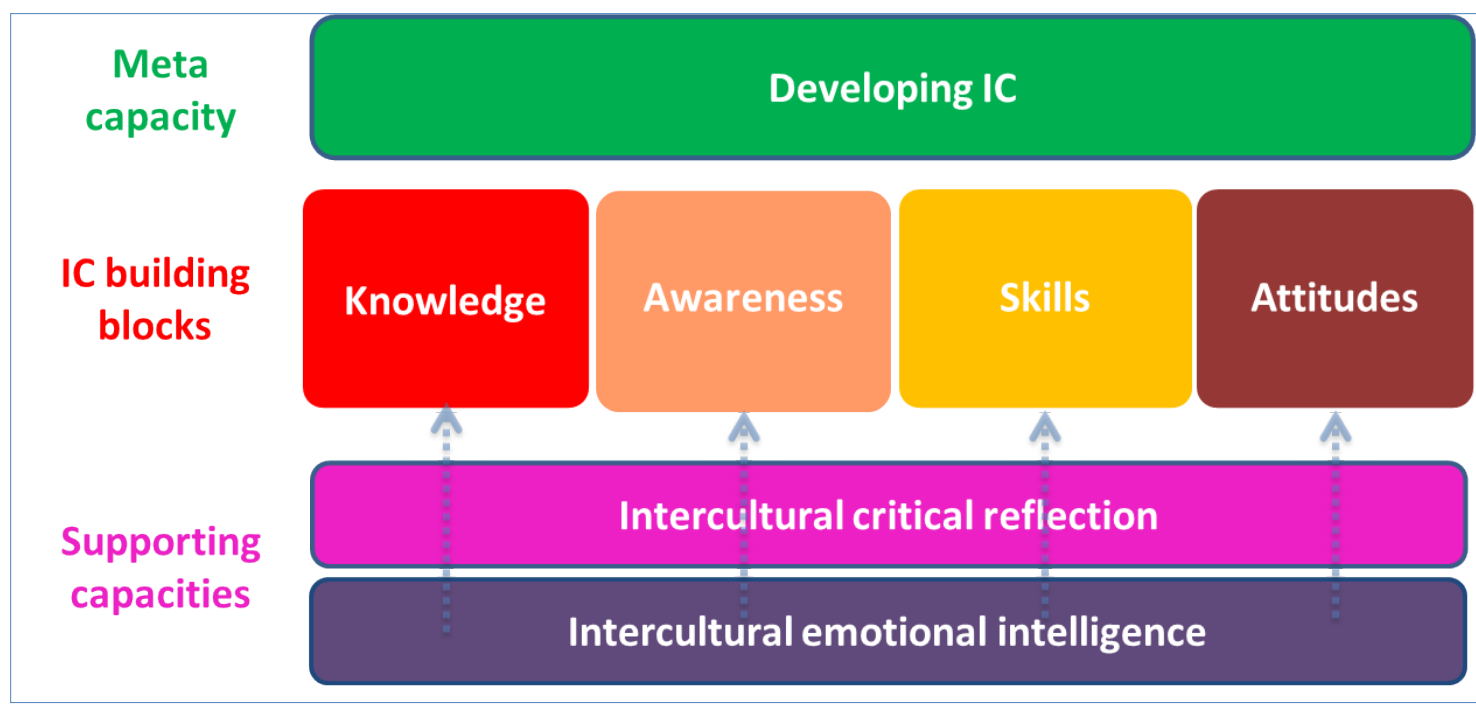

Figure 2. Erasmus Mundus Intercultural Competence (EMIC) model 


\begin{tabular}{|c|c|c|c|c|}
\hline Author(s): Model & Knowledge & Awareness & Skills & Attitudes \\
\hline $\begin{array}{l}\text { Ang, Van Dyne \& } \\
\text { Rockstuhl (2015): } \\
\text { Cultural intelligence } \\
\text { (CQ) }\end{array}$ & $\begin{array}{l}\text { "cultural-general and } \\
\text { culture-specific } \\
\text { knowledge" constitute } \\
\text { the cognitive CQ }\end{array}$ & $\begin{array}{l}\text { Awareness is part of the metacognitive } \\
\text { CQ (along with "planning" and "checking") }\end{array}$ & $\begin{array}{l}\text { Skills form part of the } \\
\text { metacognitive CQ }\end{array}$ & $\begin{array}{l}\text { Attitudes are part of the } \\
\text { motivational CQ (positive } \\
\text { attitude towards and willingness } \\
\text { to take part in intercultural } \\
\text { encounters) }\end{array}$ \\
\hline $\begin{array}{l}\text { Byram, Nichols \& } \\
\text { Stevens (2001): } \\
\text { intercultural } \\
\text { communicative } \\
\text { competence }\end{array}$ & $\begin{array}{l}\text { Knowledge of self and } \\
\text { other, of interactions at } \\
\text { individual and societal } \\
\text { level is the savoir part } \\
\text { of the competence }\end{array}$ & $\begin{array}{l}\text { Critical cultural awareness (savoir s'engager) } \\
\text { is the fifth element of the model }\end{array}$ & $\begin{array}{l}\text { Two types of skills are deemed } \\
\text { necessary: (1) skills of interpreting } \\
\text { and relating (savoir-comprendre) } \\
\text { and (2) skills of discovery and/or } \\
\text { interaction (savoir- } \\
\text { apprendre/faire) }\end{array}$ & $\begin{array}{l}\text { Attitudes of relativising self and } \\
\text { valuing other form the savoir être } \\
\text { part of the competence }\end{array}$ \\
\hline $\begin{array}{l}\text { Deardorff (2008): } \\
\text { Intercultural } \\
\text { Competence }\end{array}$ & \multicolumn{2}{|c|}{$\begin{array}{l}\text { Cultural self-awareness and sociolinguistic awareness are seen, } \\
\text { together with knowledge, as constituting a major IC category } \\
\text { Cultural self-awareness and sociolinguistic awareness are seen, } \\
\text { together with knowledge, as constituting a major IC category }\end{array}$} & $\begin{array}{l}\text { Two types of skills are } \\
\text { distinguished: listening, observing } \\
\text { and evaluating, as well as } \\
\text { analysing, interpreting and relating } \\
\text { are conceptualised as skills; while } \\
\text { "effective and appropriate } \\
\text { communication and behaviour in an } \\
\text { intercultural situation" is a separate } \\
\text { component, described as "desired } \\
\text { external outcomes" }\end{array}$ & $\begin{array}{l}\text { Two types of attitudes are } \\
\text { distinguished. Respect - valuing } \\
\text { other cultures; openness - } \\
\text { withholding judgment; and } \\
\text { curiosity \& discovery - tolerating } \\
\text { ambiguity constitute the category } \\
\text { of "attitudes"; while adaptability, } \\
\text { flexibility, ethnorelative view and } \\
\text { empathy constitute are seen as } \\
\text { "desired internal outcomes". }\end{array}$ \\
\hline $\begin{array}{l}\text { Fantini }(2006 a, b): \\
\text { Intercultural } \\
\text { communicative } \\
\text { competence (ICC) }\end{array}$ & $\begin{array}{l}\text { Knowledge is one of } \\
\text { the four ICC } \\
\text { dimensions; }\end{array}$ & $\begin{array}{l}\text { Awareness is one of the four ICC dimensions } \\
\text { viewed as central. }\end{array}$ & $\begin{array}{l}\text { Skills form one of the four ICC } \\
\text { dimensions. }\end{array}$ & $\begin{array}{l}\text { Attitudes form one of the four } \\
\text { ICC dimensions; }\end{array}$ \\
\hline $\begin{array}{l}\text { King \& Baxter } \\
\text { Magolda (2005): A } \\
\text { developmental model } \\
\text { of intercultural } \\
\text { maturity (IM) }\end{array}$ & $\begin{array}{l}\text { A "complex } \\
\text { understanding of } \\
\text { cultural differences" is } \\
\text { referred to as the } \\
\text { cognitive dimension of } \\
\text { IM }\end{array}$ & $\begin{array}{l}\text { Awareness forms part of all the three } \\
\text { dimensions of IM; the initial level of the } \\
\text { three is characterised by a lack of awareness, } \\
\text { which is expected to be developed at the } \\
\text { intermediate level and is actively acted upon } \\
\text { at the mature level of development. }\end{array}$ & $\begin{array}{l}\text { Skills are brought together under } \\
\text { the label of "capacity to function } \\
\text { interdependently with diverse } \\
\text { others" and constitute the } \\
\text { interpersonal dimension of IC }\end{array}$ & $\begin{array}{l}\text { "Capacity to accept and not feel } \\
\text { threatened by cultural } \\
\text { differences" is the essence of the } \\
\text { intrapersonal dimension of IM. }\end{array}$ \\
\hline $\begin{array}{l}\text { Williams (2009): } \\
\text { Reflective model of } \\
\text { intercultural } \\
\text { competence }\end{array}$ & $\begin{array}{l}\text { "Knowledge about } \\
\text { cultural norms, values, } \\
\text { behaviours, and } \\
\text { issues" constitute the } \\
\text { cognitive dimension of } \\
\text { IC }\end{array}$ & $\begin{array}{l}\text { Awareness, although not conceptualised as a } \\
\text { separate dimension, is regarded both as the } \\
\text { principle that guides and frames IC } \\
\text { development and as a possible outcome of } \\
\text { the cognitive aspect of IC development }\end{array}$ & $\begin{array}{l}\text { Behavioural dimension comprises } \\
\text { "critical skills such as } \\
\text { resourcefulness, problem-solving } \\
\text { skills, and culturally appropriate } \\
\text { people skills" }\end{array}$ & $\begin{array}{l}\text { Attitudes of flexibility and open- } \\
\text { mindedness constitute the } \\
\text { affective dimension of IC }\end{array}$ \\
\hline
\end{tabular}

Table 1. Knowledge, awareness, skills, and attitudes (KASA) as core IC element types (theoretical models ordered alphabetically) 


\begin{tabular}{|l|c|c|c|c|l|}
\hline $\begin{array}{l}\text { Master Programme/ } \\
\text { Type of respondent }\end{array}$ & WOP-P & MALLL & EUROMIME & GIM & Total \\
\hline $\mathbf{1}^{\text {st-year students }}$ & 4 & 4 & 2 & 6 & $16(38.1 \%)$ \\
\hline $2^{\text {nd-year students }}$ & 3 & 0 & 1 & 0 & $4(9.5 \%)$ \\
\hline Graduates & 3 & 2 & 2 & 2 & $9(21.4 \%)$ \\
\hline Academics & 2 & 4 & 1 & 2 & $9(21.4 \%)$ \\
\hline Administrative support & 1 & 1 & 1 & 1 & $4(9.5 \%)$ \\
\hline Total & 13 & $\begin{array}{c}11 \\
(26.2 \%)\end{array}$ & $\begin{array}{c}7 \\
(16.7 \%)\end{array}$ & $\begin{array}{c}11 \\
(26.2 \%)\end{array}$ & 42 \\
\hline
\end{tabular}

Table 2. Sample: number of respondents by category and EMJMD programme 


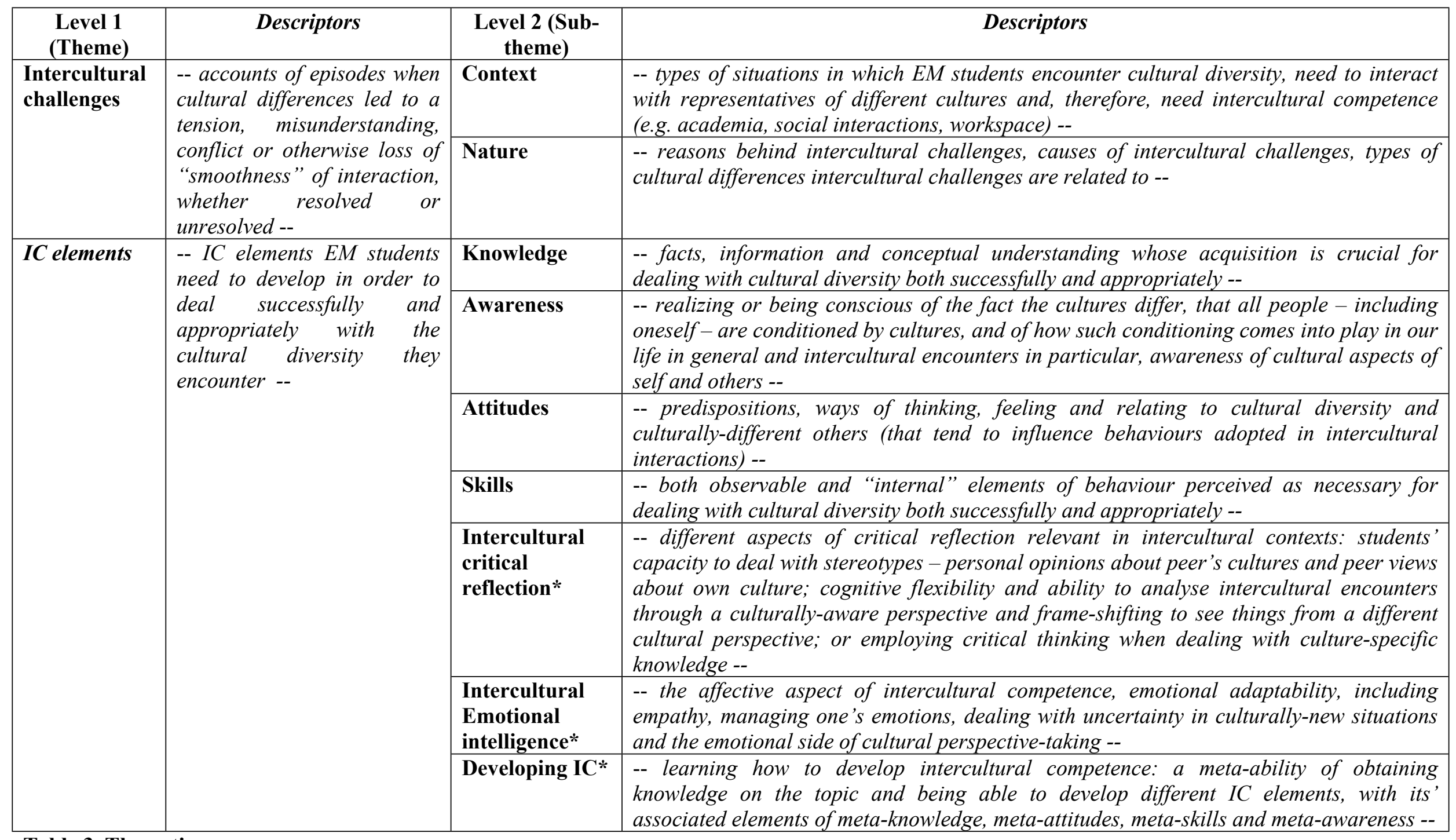

Table 3. Thematic map 


\begin{tabular}{|l|l|}
\hline Context & Challenges \\
\hline \multirow{5}{*}{$\begin{array}{c}\text { Academic: within the } \\
\text { university }\end{array}$} & $\begin{array}{l}\text { (1) Studying at different foreign universities; not necessarily in } \\
\text { exactly the same field as ones' undergraduate degree [Academic } \\
\text { Cultures] }\end{array}$ \\
\cline { 2 - 2 } $\begin{array}{l}\text { (2) EMJMD programme being different from other academic } \\
\text { programmes; the feeling of EM students being very different } \\
\text { from other students [Programme] }\end{array}$ \\
\hline $\begin{array}{l}\text { (3) Heterogeneity of the EMJMD group; diversity students } \\
\text { encounter within the group of their classmates [Group] }\end{array}$ \\
\hline \multirow{3}{*}{$\begin{array}{c}\text { Social life: outside the } \\
\text { university }\end{array}$} & $\begin{array}{l}\text { (4) Living in the same flat with people from other cultures [Flat] } \\
\text { (5) Complex logistics of the EMJMDs [Logistics] }\end{array}$ \\
\hline $\begin{array}{l}\text { (6) Cultural differences among the locals and EM students } \\
\text { [National Cultures] }\end{array}$ \\
\hline
\end{tabular}

Table 4. Contexts of intercultural challenges 


\begin{tabular}{|l|r|r|r|r|r|r|}
\hline Context & Behaviours & Communication & Values & $\begin{array}{l}\text { Low } \\
\text { IC } \\
\text { others }\end{array}$ & $\begin{array}{l}\text { Low } \\
\text { IC } \\
\text { own }\end{array}$ & $\begin{array}{l}\text { Personal } \\
\text { challenges }\end{array}$ \\
\hline $\begin{array}{l}\text { Academic } \\
\text { Cultures }\end{array}$ & 23 & 22 & 22 & 1 & 3 & 13 \\
\hline $\begin{array}{l}\text { EMJMD } \\
\text { Programme }\end{array}$ & 1 & 1 & 2 & 1 & 1 & 4 \\
\hline $\begin{array}{l}\text { EMJMD } \\
\text { group }\end{array}$ & 9 & 4 & 8 & 1 & 1 & 8 \\
\hline Flat & 16 & 12 & 10 & 2 & 4 & 16 \\
\hline Logistics & 3 & 2 & 1 & 0 & 0 & 5 \\
\hline $\begin{array}{l}\text { National } \\
\text { culture }\end{array}$ & 13 & 7 & 12 & 3 & 4 & 19 \\
\hline
\end{tabular}

Table 5. Intercultural challenges reported: number of interviewees reporting each challenge 


\begin{tabular}{|c|c|c|c|c|c|c|c|}
\hline $\begin{array}{l}\text { Context/ } \\
\text { Nature }\end{array}$ & $\begin{array}{l}\text { Behaviour } \\
\text { s }\end{array}$ & Communication & Values & $\begin{array}{l}\text { Low IC } \\
\text { others }\end{array}$ & $\begin{array}{l}\text { Low IC } \\
\text { own }\end{array}$ & $\begin{array}{l}\text { Personal } \\
\text { challenges }\end{array}$ & Total \\
\hline Academic & 60 & 36 & 42 & 1 & 4 & 19 & $\begin{array}{c}162 \\
(40.3 \%)\end{array}$ \\
\hline $\begin{array}{l}\text { EMJMD } \\
\text { Programme }\end{array}$ & 1 & 1 & 2 & 1 & 1 & 7 & $\begin{array}{c}13 \\
(3.2 \%) \\
\end{array}$ \\
\hline Flat & 14 & 7 & 9 & 1 & 1 & 12 & $\begin{array}{c}44 \\
(10.9 \%)\end{array}$ \\
\hline $\begin{array}{l}\text { EMJMD } \\
\text { group }\end{array}$ & 28 & 24 & 15 & 2 & 4 & 21 & $\begin{array}{c}94 \\
(23.4 \%) \\
\end{array}$ \\
\hline Logistics & 3 & 2 & 1 & 0 & 0 & 6 & $\begin{array}{c}12 \\
(3 \%) \\
\end{array}$ \\
\hline $\begin{array}{l}\text { National } \\
\text { culture }\end{array}$ & 17 & 7 & 15 & 4 & 5 & 29 & $\begin{array}{c}77 \\
(19.2 \%)\end{array}$ \\
\hline Total & $\begin{array}{c}123 \\
(30.6 \%)\end{array}$ & $\begin{array}{c}77 \\
(19.2 \%)\end{array}$ & $\begin{array}{c}84 \\
(20.9 \%)\end{array}$ & $\begin{array}{c}9 \\
(2.2 \%)\end{array}$ & $\begin{array}{c}15 \\
(3.7 \%)\end{array}$ & $94(23.4 \%)$ & $\begin{array}{c}402 \\
(100 \%)\end{array}$ \\
\hline
\end{tabular}

Table 6. Intercultural challenges reported: number of references 


\begin{tabular}{|c|c|c|c|c|c|c|}
\hline \multirow[t]{3}{*}{ IC element } & \multicolumn{6}{|c|}{ Number of references } \\
\hline & \multicolumn{2}{|c|}{ Students reporting } & \multirow{2}{*}{$\begin{array}{l}\text { Staff } \\
\text { reporting } \\
\text { for } \\
\text { students }\end{array}$} & \multirow{2}{*}{\begin{tabular}{|l|} 
Total by \\
respondents
\end{tabular}} & \multirow{2}{*}{$\begin{array}{l}\text { Identified } \\
\text { by } \\
\text { researchers }\end{array}$} & \multirow[t]{2}{*}{ Total } \\
\hline & $\begin{array}{l}\text { For } \\
\text { oneself }\end{array}$ & $\begin{array}{l}\text { For other } \\
\text { students }\end{array}$ & & & & \\
\hline Knowledge & 0 & 19 & 1 & $20(12.4 \%)$ & 14 & $34(12.3 \%)$ \\
\hline Attitudes & 2 & 10 & 7 & $19(11.8)$ & 3 & $22(7.9 \%)$ \\
\hline Skills & 10 & 10 & 9 & $29(18 \%)$ & 10 & $40(14.4 \%)$ \\
\hline Awareness & 9 & 17 & 6 & $32(19.9 \%)$ & 10 & $42(15.2 \%)$ \\
\hline $\begin{array}{l}\text { Intercultural } \\
\text { critical } \\
\text { reflection }\end{array}$ & 7 & 8 & 5 & $20(12.4 \%)$ & 15 & $35(12.6 \%)$ \\
\hline $\begin{array}{l}\text { Intercultural } \\
\text { emotional } \\
\text { intelligence }\end{array}$ & 4 & 4 & 5 & $13(8 \%)$ & 4 & $17(6.1 \%)$ \\
\hline Developing IC & 10 & 5 & 13 & $28(17.4 \%)$ & 59 & $87(31.4 \%)$ \\
\hline
\end{tabular}

Table 7. IC elements: number of references 